\title{
CORRECTION
}

\section{Correction to: Solution of the weighted symmetric similarity transformations based on quaternions}

\author{
H. Mercan ${ }^{1} \cdot$ O. Akyilmaz ${ }^{1}$ (D) C. Aydin $^{2}$ (I)
}

Published online: 16 July 2018

c) Springer-Verlag GmbH Germany, part of Springer Nature 2018

\section{Correction to: Journal of Geodesy https://doi.org/10.1007/s00190-017-1104-0}

In the original article, Eq. (19), the covariance matrix of the source coordinates in the second term in the parenthesis, $\boldsymbol{\Sigma}_{x y z}$, has been incorrectly written as $\boldsymbol{\Sigma}_{X Y Z}$. Thus, Eq. (19) is incorrect, and we suggest the following correct form instead:

$$
\hat{\boldsymbol{\Sigma}}_{\xi}=\hat{\sigma}_{0}^{2}\left(\tilde{\boldsymbol{A}}_{0}^{\mathrm{T}}\left(\boldsymbol{\Sigma}_{X Y Z}+\tilde{\boldsymbol{B}}_{2_{0}}^{\mathrm{T}} \boldsymbol{\Sigma}_{x y z} \tilde{\boldsymbol{B}}_{2_{0}}\right)^{-1} \tilde{\boldsymbol{A}}_{0}\right)^{-1},
$$

The other equations in the original article are unaffected by the error in Eq. (19).

\section{O. Akyilmaz \\ akyilma2@itu.edu.tr \\ H. Mercan \\ mercanh@itu.edu.tr \\ C. Aydin \\ caydin@ytu.edu.tr}

1 Department of Geomatics, Istanbul Technical University, 34469 Maslak, Istanbul, Turkey

2 Department of Geomatics, Yildiz Technical University, 34201 Esenler, Istanbul, Turkey 